\title{
ENTRETEJER EL PENSAR PARA RELACIONAR EL HACER
}

Itziar Zubillaga Ruenes

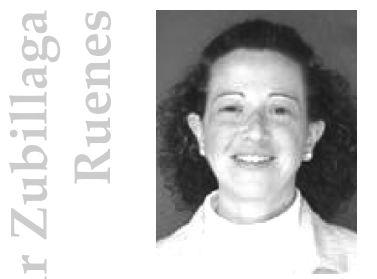

Doctoranda en Pedagogía, Universidad Popular Autónoma del Estado de Puebla (UPAEP). Maestría en Psicología Educativa, Universidad del Desarrollo del Estado de Puebla (UNIDES). Especialidad en Problemas de Aprendizaje, Universidad de las Américas del DF (UDLA). Licenciatura en Pedagogía, Universidad Panamericana, México.

\section{RESUMEN}

Este texto se dirige a los protagonistas de la educación superior. Su principal intención es expresar cómo, desde el aula universitaria, puede lograrse que el estudiante - con apoyo del docente y con base en el contenido curricular derivado en actividades concretas-, elabore productos de aprendizaje ${ }^{1}$, acordes al desarrollo del pensamiento complejo.

1 Productos de aprendizaje es el resultado que representa los contenidos temáticos de una asignatura que conlleva un sustento teórico y que puede ser presentado en diversidad de modalidades, acordes con las sugerencias incluidas en el artículo. 
El artículo hace hincapié en la educación superior áulica, intentando mejorar el proceso de enseñanza-aprendizaje; mejorarlo desde la perspectiva de complejizar el pensar para expresarlo en un hacer con sentido de aprendizaje profundo; hacer camino para lograr que el docente y el estudiante «utilicen los procesos de nivel cognitivo superior» (Biggs, 2005), considerando a los productos de aprendizaje como medios para ese logro.

Palabras clave: educación superior; pensamiento complejo; proceso enseñanza aprendizaje; producción académica.

\section{ABSTRACT}

This text is for teachers and students in bachelor degree and so on, that has the intention of being better in the teaching-learning process by elaborating learning products, based on curricula and specific activities with the help of complex thinking.

Key words: bachelor degree; complex thinking; teaching-learning process; learning products.

\section{INTRODUCCIÓN}

El aula universitaria implica a sus dos protagonistas (docente-estudiante) relacionados por el proceso de enseñanza-aprendizaje desde su cognición, en donde los procesos superiores (idea, juicio, pensamiento, resolución de problemas, reflexión) son el inicio de la posibilidad de mejora con base en el pensamiento complejo ${ }^{2}$, aterrizado en productos de aprendizaje escogidos y elaborados ad hoc al estudiante y a la naturaleza propia del contenido temático enseñado.

2 Según Edgar Morin, el pensamiento complejo es «pensar trascendiendo la complicación (es decir las inter-retroacciones innombrables), trascendiendo las incertidumbres y las contradicciones» Cfr. Morin, Introducción al pensamiento complejo. 
Dentro del aula universitaria se educa, considerando al término como un concepto clave que se comprende como «auto-tarea ayudada» (Bernal González y Meza Mejía, 2007), en una doble vertiente. En la primera, se encuentra el desarrollo madurativo de cada aspecto potencial del ser humano (educabilidad). La segunda vertiente es dotar, desde el exterior, con los medios necesarios para disponer esas potencialidades (educatividad). Educabilidad y educatividad diagnostican, planean, construyen-deconstruyen y dan seguimiento a la educación,

[...] que saca al ser humano de su encierro egocéntrico para diferenciar sus intereses, y, con ello, [el] aumento de su capacidad de dolor y de gozo, la formación del sentido de los valores, del sentido de su jerarquía, de la capacidad para distinguir lo más importante de lo menos, es una condición para el éxito de la vida individual y para la comunicación con los demás (Villalobos Pérez-Cortés, 2003) [...]

es parte del plan de la trayectoria o recorrido del ser humano sobre la tierra, distinguiendo lo permanente de lo cambiante ${ }^{3}$.

Tanto el docente como el estudiante universitario son quienes desarrollan

[...] un componente actitudinal basado en un comportamiento ético; los esquemas de pensamiento, reflejado en la capacidad de analizar y sintetizar, de resolver problemas; el uso de la comunicación para expresarse de manera oral y por escrito, y con la disposición para el trabajo (Universidad de la República, 2004)

3 «Las ciencias abrieron sus fronteras y aprendieron, además de sus propias certezas, la incertidumbre, la inestabilidad, las variaciones, la irreversibilidad, en fin: la interdependencia. Bajo esta forma compleja, hoy es necesario entender la innovación de los métodos didácticos desde la frontera de los nuevos conocimientos, pero sustentados desde lo permanente de la educación. Lo perenne de los métodos didácticos es su esencia, fundamentada en una teoría pedagógica con asideros filosóficos, psicológicos, sociológicos; lo permanente persiste y solo se enriquece. La innovación basada en lo cambiante es solo moda pasajera» Cfr. Villalobos, op.cit., p. 14. 
colaborativo, además de habilidades propias de su campo profesional de estudio.

Ambos tienen la capacidad de pensamiento, que se desarrolla en pro de su vida en general y de su campo profesio-vocacional. Docente y estudiante están relacionados en el proceso de enseñanza-aprendizaje por medio del pensar, que guía por los caminos que se estructuran, elaboran, reajustan sobre la marcha, para descubrir, aportar, complejizar nuevas posibilidades que dejen huella en y para la humanidad.

Dentro de la educación formal universitaria existen posibilidades que permiten entrelazar variedad de aspectos de la complejidad humana; uno de ellos es el desarrollo cognitivo en su expresión máxima: el pensamiento complejo que acoge al «conocimiento científico, al conocimiento práctico, las creencias y la evidencia del no saber, amenazadas por tendencias unidimensionales del pensamiento positivo» (Morin, 2003). La investigación ha dotado de extensas y profundas aportaciones científicas, y también ha alejado al ser humano de sus propias investigaciones.

Con base en lo anterior, este trabajo es una propuesta de apertura en donde el pensar entretejido esté al servicio del hacer con sentido para que los contenidos curriculares incluyan al ser humano ${ }^{4}$ como capaz de aprender a la luz de diversidad de estrategias de

4 Se aclara con esta afirmación que el positivismo, por su válida tendencia a la objetividad, ha relegado al investigador en cuanto a su criterio, a su afectividad, a sus interacciones sociales, creyendo que esta postura acerca a la exactitud y precisión de lo investigado, sin considerar que el trabajo intelectual, los afectos y las relaciones interpersonales no pueden desprenderse del ser que las realiza, es decir, que son intrínsecas e inherentes a su autor. Es necesario dar cabida, en y con todo su ser, a quien aporta ciencia; solo así persiste la integridad e integralidad, mismas que evitan la subjetividad. 
enseñanza-aprendizaje ${ }^{5}$, dinámicas, propositivas, flexibles, capaces de acoplarse a cualquier estilo de aprender y de enseñar; en pocas palabras, para lograr una integralidad sin importar cuál sea el medio estratégico, y a la vez sin olvidar un comportamiento ético de parte de los protagonistas de la educación universitaria: estudiante-docente.

\section{LA COGNICIÓN PERMITE EL ENTRETEJIMIENTO DEL PENSAR. REFERENTES TEÓRICOS}

En las teorías paradigmáticas contemporáneas del desarrollo cognitivo - en concreto, la de los sistemas dinámicos-, el ser humano, junto con cada uno de los contextos y de los objetos existentes, son relacionales, se implican y se evita considerarlos como agregados, como piezas aisladas.

En este marco, se asume que lo biológico y lo socio-cultural constituyen subsistemas compenetrados e interdependientes que emergen desde un sistema auto-organizado [...] (Gutiérrez Martínez, 2005).

Esto significa que los estados de equilibrio son aparentes, ya que en realidad se fluctúa entre el orden y el desorden; existe intermitencia entre el orden (estático) y el desorden (dinámico) ${ }^{6}$; es un continuo de

5 Entendidas como planes de acción que sirven de mediadores para que la cognición humana construya, aprehenda, adecue, y organice lo necesario con ayuda de su capacidad intelectual, aptitudes y habilidades que conduzcan al conocimiento superficial y/o profundo. «La estrategia didáctica da respuesta a cómo llevar a cabo el proceso de enseñanza y para ello se apoya en diferentes técnicas, medios y en un sistema de comunicación o herramientas capaces de facilitar las diferentes actividades comunicativas y la distribución de materiales de enseñanza» (Salinas, Pérez y de Benito, 2008).

6 «La teoría del caos ha supuesto una sacudida a cualquier concepción de la teoría en cualquier ámbito; cómo hemos visto, reconstruye las teorías desarrolladas, y en nuestro caso, sinceramente, creo que la teoría de la educación no puede mantenerse por más tiempo sobre la base de configuraciones ordenadas y sistematizadas del hecho pedagógico ya que [...] la realidad nos indica que toda ordenación educativa es fruto de una situación caótica previa (diferencias en el punto de partida). Por tanto, creemos que no estaría de más considerar lo caótico de y en la educación» (Colom, 2002). Se inicia esta época educativa con las tendencias hacia lo general; solo es necesario recordar que el ser humano requiere de una vertiente axiológica que le otorgue congruencia entre el ser, pensar y actuar; en pocas palabras, el caos ha de evitarse en la vida ética, de lo contrario, en lugar de complejizar se complica la existencia humana. 
vida en donde se encuentra la flexibilidad como amortiguador que permite actualizar patrones de organización interna y de interacción con el medio, mostrados en la conducta de cualquier ser humano, «de ahí que resulte compleja y variable» (Gutiérrez Martínez, 2005). Compleja por sus interacciones y por su relación con lo permanente: el comportamiento ético. Variable por su continua capacidad de aprendizaje: lo cambiante.

El conocimiento en los sistemas dinámicos

[...] es un proceso entendido como un potencial que se va realizando en el mismo momento de la ejecución, y por tanto, de manera variable en función de los contextos específicos (Gutiérrez Martínez, 2005),

que con ayuda de la reflexión conduce hacia el aprendizaje, mismo que puede conjuntar al conocimiento con la actividad y la propia manera de ser. Este proceso de aprendizaje se gesta a lo largo de la vida considerando la posibilidad de:

- Multiplicidad de maneras o alternativas de pensamiento de un hecho, fenómeno o circunstancia.

- «Cambios en la frecuencia de uso de tales modalidades e introducción de nuevas maneras de pensamiento» (Gutiérrez Martínez, 2005) entretejidas, simulando curvas en donde el valle es el desorden y la cresta es el orden.

- «Los cambios son el resultado de mecanismos activos de autorregulación» (Gutiérrez Martínez, 2005). Cambios debidos a las nuevas adquisiciones del saber; autorregulación como la capacidad de autogobernarse, de adquirir y demostrar la madurez con base en la etapa de la vida por la que se esté transitando.

Estos supuestos del aprendizaje en los sistemas dinámicos permean entre lo permanente y lo cambiante en el ser humano. 
De lo anterior se concluye que el aprendizaje es parte de la cognición y es

[...] consecuencia de una práctica social en un mundo de negociación y administración de significados compartidos que conducen a la generación de pensamiento complejo (López Carrasco, 2008).

Los significados compartidos permiten observar que el aprendizaje profundo ${ }^{7}$ "es una actividad crucial en cualquier cultura» (Anderson, 2001). La enseñanza es como un vertedero de orientaciones, guías, propuestas, de diversidad de asuntos desde la perspectiva experta. De ambas concepciones puede considerarse al ser humano como sistema abierto entre lo privado (en sí mismo, el pensamiento complejo) y lo público (social y cultural).

Para enseñar y para aprender es necesario pensar, y para pensar, siendo estudiante o docente universitario, es inminente complejizar; por lo tanto, el pensamiento complejo es la alternativa.

De ascendencia etimológica latina, «complejidad» surge de

complectere, cuya raíz es plectere, que significa trenzar, enlazar; el prefijo com añade el sentido de dualidad de dos elementos opuestos, sin anularse. Se integra al castellano durante el primer cuarto del siglo XVII con el vocablo complexo cuyo significado es que abarca (Universidad del Salvador, USAL, 2007).

El pensamiento complejo significa relacionar la simplicidad, la sencillez con la que se pretende comprender la realidad; es integrar el punto de vista del pensante, quien ha de ir de lo global al detalle y viceversa, llegando a entreverar los conocimientos para aportar mejoras que permitan el perfeccionamiento. Pensar con complejidad en la educación superior es un acto holístico, y a la vez reductivo e individual; es considerar al todo como un macro conformado por sus micros y cada uno de ellos en su esencia y ser, y como parte del todo.

7 Es aquel aprendizaje que penetra en los diferentes puntos de vista que lo envuelven; es en el que la persona aprehende, hace suyo. 
El pensamiento complejo en la universidad es evitar la parcialización de las ciencias y las disciplinas al considerarlas por separado ${ }^{8}$... Ya es tiempo de entreverarlas para llegar a la integralidad del aprendizaje de acuerdo a cada estudiante y a cada profesor, en su particular manera de estar en la realidad.

\section{EL PENSAR ENTRETEJIDO GUÍA AL HACER RELACIONADO CON SENTIDO}

Cuando el profesor universitario enseña con sentido de unión, de relación, de urdimbre de los conocimientos, de aceptación de otras ciencias, disciplinas y saberes, como parte inherente de la realidad planetaria, y acepta su propio estilo de aprender y el de sus estudiantes, puede facilitar la unión entre contenidos curriculares y experiencias de la vida ${ }^{9}$, permitiendo que el estudiante exprese su aprendizaje en diferentes modalidades, para difundir el conocimiento por medio de diversidad de productos de aprendizaje académico con un fin de bien.

De lo anterior se deriva un cuestionamiento, ¿por qué la pedagogía, considerada como el saber profundo de la educación, suele permanecer en la teoría y evita generalmente conjuntarse con la práctica?

Es necesaria la conexión del pensamiento complejo con la realidad vivida, y es la pedagogía la que con sus para qué (desarrollo de competencias), sus qué (contenidos, teoría), y sus cómo (medios para llegar al fin), encamina a y se relaciona con todas las ciencias, disciplinas y

8 «Ambos conceptos, enfoques y enseñanza, se han integrado mediante el concepto de sistema. Los árboles se convierten en bosque, se produce un cambio cualitativo en el aprendizaje y la comprensión. Ya no se trata de hacer una lista de datos y detalles: abordan un punto, dándole sentido a la luz de su contribución al tema en su conjunto. Este es el primer nivel en el que puede utilizarse adecuadamente el término comprensión en un sentido académicamente relevante» (Biggs, 2005). La comprensión es un proceso de paso a paso; evita ser un bloque que sorprende y se aprehende de golpe; se constituye primero a nivel declarativo para luego conjuntarse con otros conocimientos, habilidades y actitudes, y ser aplicable a la vida real.

9 «El aprendizaje informal es un aspecto significativo de nuestra experiencia de aprendizaje. La educación formal ya no constituye la mayor parte de nuestro aprendizaje. El aprendizaje ocurre ahora en una variedad de formas - a través de comunidades de práctica, redes personales, y a través de la realización de tareas laborales» (Siemens, 2004). 
saberes para apoyarlas en la mejora del inseparable binomio enseñanza-aprendizaje. La congruencia surge entre el pensamiento entretejido de conocimientos y su transferencia hacia la actividad con sentido;

[...] el trabajar no solo con lo que sabe el estudiante, sino aprovechar lo que el alumno sabe hacer con lo que sabe (López Carrasco, 2008),

permite el cambio en la educación superior, considerando a las aulas universitarias, con sus protagonistas, como comunidades de intercambio de la enseñanza y del aprendizaje, en donde la colaboración permea la dinámica, y se promueve un ganar-ganar-ganar (estudiantes-profesores-sociedad).

Colaborar para un fin, con proyectos concretos, proporciona sentido al hacer y promueve «una interacción no solo didáctica sino personal» (López Carrasco, 2008); existe una interrelación entre iguales que evita limitarse a los contenidos; va más allá para relacionar docentes ${ }^{10}$, estudiantes y conocimientos.

\section{PENSAR Y HACER, UN MARIDAJE EN DONDE EL «CÓMO» PERMITE LA LIBERTAD DE ACTIVIDADES}

Se propone que para lograr el maridaje entre pensar y hacer, se encuentren caminos de aprendizaje-enseñanza ${ }^{11}$, que puedan expresarse en productos de aprendizaje académico concreto: los "cómo", los medios que reflejan un pensamiento y un quehacer con sentido,

${ }^{10}$ «[...] el nuevo docente no puede reducir su quehacer a la estricta transmisión de información, incluso ni siquiera a ser un simple facilitador del aprendizaje, sino que tiene que mediar el encuentro de sus estudiantes con el conocimiento, en el sentido de guiar y orientar la actividad de los mismos, asumiendo el rol de profesor constructivo y reflexivo» (Villaruel, 2009). La vocación docente es el profundo compromiso de servir al otro con la definida intencionalidad de enseñarse y aprenderse, proceso diádico.

${ }^{11}$ Se entienden como conjunto de actividades, técnicas y medios que se planifican de acuerdo con las necesidades de la población a quien se dirigen; varían de acuerdo con los objetivos y contenidos de estudio, así como de los aprendizajes previos, posibilidades, capacidades y limitaciones de los profesores y de los estudiantes; son un componente fundamental en el proceso de enseñanza-aprendizaje ya que guían las acciones para que cumplan su fin, y han de ser conscientes e intencionales. 
y que han de permitirse de acuerdo al estilo personal ${ }^{12}$. Los productos de aprendizaje académico motivan a aprender, «la motivación es el motor que impulsa a realizar actividades que dejan una sensación de satisfacción» (Negrete, 2008)... ¿Qué mejor, entonces, que permitir la satisfacción de cada estudiante en una obra de trabajo bien hecho!

Los productos de aprendizaje académico son innovaciones que buscan implementar y poner a prueba nuevas prácticas para lograr el aprendizaje y conciliar la teoría que, en no pocas ocasiones, es antagónica. Los antagonismos, los errores, las incertidumbres científicas son parte del pensamiento complejo, mismo que puede desarrollarse plasmándolo en los productos de aprendizaje académico, pues esta una manera de analizarlos, generalizarlos, posibilitar la reflexión y tomar postura.

Con base en lo anterior, se sugieren algunos productos de aprendizaje académico ya conocidos. Cabe señalar que dichos productos de aprendizaje académico son meras sugerencias, útiles como medio, reconociendo la existencia de más variedad.

${ }_{12}$ Entendido como las tendencias modales que caracterizan a una persona para aprender conocimientos, habilidades y/o actitudes. 


\begin{tabular}{|c|c|c|}
\hline $\begin{array}{l}\text { PRODUCTO DE } \\
\text { APRENDIZAJE } \\
\text { ACADÉMICO }\end{array}$ & DESCRIPCIÓN & MODALIDAD \\
\hline $\begin{array}{l}\text { Análisis de } \\
\text { situaciones complejas: }\end{array}$ & $\begin{array}{l}\text { Planteamientos reales con } \\
\text { soluciones divergentes cuya } \\
\text { finalidad es "generar dile- } \\
\text { mas y controversias que se } \\
\text { vinculan directamente con el } \\
\text { currículo y que por medio de } \\
\text { preguntas de estudio para su } \\
\text { análisis, se trabaja en peque- } \\
\text { ños grupos» (Díaz Barriga, } \\
\text { 2006). El experto redacta la } \\
\text { situación y plantea los objeti- } \\
\text { vos de la actividad; el estu- } \\
\text { diante lee, investiga, analiza } \\
\text { y piensa relacionalmente } \\
\text { para aportar posibles } \\
\text { soluciones. }\end{array}$ & $\begin{array}{l}\text { Impreso. } \\
\text { Electrónico. }\end{array}$ \\
\hline Artículos: & $\begin{array}{l}\text { Documento científico o de } \\
\text { divulgación que expresa } \\
\text { temas actualizados que per- } \\
\text { miten dar a conocer investi- } \\
\text { gaciones, ideas, propuestas, } \\
\text { debates, etcétera. Su exten- } \\
\text { sión es breve en compara- } \\
\text { ción con un libro. Su inten- } \\
\text { ción final ha de ser la } \\
\text { publicación. }\end{array}$ & $\begin{array}{l}\text { Impreso. } \\
\text { Electrónico. } \\
\text { Audio. }\end{array}$ \\
\hline
\end{tabular}




\begin{tabular}{|c|c|c|}
\hline $\begin{array}{l}\text { PRODUCTO DE } \\
\text { APRENDIZAJE } \\
\text { ACADÉMICO }\end{array}$ & DESCRIPCIÓN & MODALIDAD \\
\hline Blog: & $\begin{array}{l}\text { Espacio electrónico disponi- } \\
\text { ble en la World Wide Web } \\
\text { (www) que, desde el punto } \\
\text { de vista académico, es útil } \\
\text { para expresar contenidos } \\
\text { curriculares de diversos } \\
\text { temas. Se caracteriza por } \\
\text { contener espacios con infor- } \\
\text { mación permanente y con } \\
\text { textos frecuentemente actua- } \\
\text { lizados por los estudiantes y } \\
\text { docentes, que son ordenados } \\
\text { cronológicamente del más al } \\
\text { menos reciente; las actuali- } \\
\text { zaciones son consideradas } \\
\text { como aportaciones al conte- } \\
\text { nido central, que incorporan } \\
\text { diversidad de puntos de vista } \\
\text { basados en fundamentos teó- } \\
\text { ricos. Se puede traducir como } \\
\text { «bitácora electrónica». }\end{array}$ & Electrónico. \\
\hline Correo electrónico: & $\begin{array}{l}\text { Protocolo de comunicación } \\
\text { en tiempo diferido, con la } \\
\text { posibilidad de intercambiar } \\
\text { diálogo escrito y documen- } \\
\text { tos afines a un tema } \\
\text { concreto, seleccionado del } \\
\text { contenido. }\end{array}$ & Electrónico. \\
\hline
\end{tabular}




\begin{tabular}{|c|c|c|}
\hline $\begin{array}{l}\text { PRODUCTO DE } \\
\text { APRENDIZAJE } \\
\text { ACADÉMICO }\end{array}$ & DESCRIPCIÓN & MODALIDAD \\
\hline $\begin{array}{l}\text { Diagramas } \\
\text { (mapa mental, } \\
\text { cuadro sinóptico, } \\
\text { etcétera): }\end{array}$ & $\begin{array}{l}\text { Esquematizaciones semánti- } \\
\text { cas, sin esquema lineal, sur- } \\
\text { gidas de la reflexión; elabo- } \\
\text { radas con base en la estruc- } \\
\text { tura mental personal, al ligar } \\
\text { y relacionar una serie de } \\
\text { palabras que, vistas como un } \\
\text { todo, expresan una síntesis } \\
\text { del aprendizaje global. }\end{array}$ & $\begin{array}{l}\text { Impreso. } \\
\text { Electrónico. }\end{array}$ \\
\hline Diarios: & $\begin{array}{l}\text { Documentos que permiten el } \\
\text { relato de experiencias de } \\
\text { aprendizaje -en donde se } \\
\text { incluyen pensamientos per- } \\
\text { sonales y reacciones-, rela- } \\
\text { cionando la narración de la } \\
\text { experiencia «con los concep- } \\
\text { tos clave y lo vincula con el } \\
\text { contenido del curso o de la } \\
\text { disciplina. También se pue- } \\
\text { den agregar valores, objeti- } \\
\text { vos, actitudes, aprendizajes } \\
\text { que se logran» (Díaz Barriga, } \\
\text { 2006). }\end{array}$ & $\begin{array}{l}\text { Impreso. } \\
\text { Electrónico. } \\
\text { Audio. }\end{array}$ \\
\hline
\end{tabular}




\begin{tabular}{|c|c|c|}
\hline $\begin{array}{l}\text { PRODUCTO DE } \\
\text { APRENDIZAJE } \\
\text { ACADÉMICO }\end{array}$ & DESCRIPCIÓN & MODALIDAD \\
\hline Documento experiencial: & $\begin{array}{l}\text { Documentos que surgen del } \\
\text { servicio en entornos propios } \\
\text { de una comunidad, cuyo } \\
\text { contenido «describe e inter- } \\
\text { preta la experiencia de servi- } \\
\text { cio, donde se incluyen pro- } \\
\text { puestas» (Díaz Barriga, 2006) } \\
\text { de mejora, apoyados en } \\
\text { bibliografía relacionada. }\end{array}$ & $\begin{array}{l}\text { Impreso. } \\
\text { Electrónico. } \\
\text { Audio. }\end{array}$ \\
\hline Exhibición museográfica: & $\begin{array}{l}\text { Montaje de diversidad de } \\
\text { objetos y/o documentos que } \\
\text { expresan - visual, auditiva } \\
\text { y/o interactivamente, con } \\
\text { explicaciones que les acom- } \\
\text { pañan-, diversos puntos de } \\
\text { vista acerca del tema central } \\
\text { de la exhibición, extraído del } \\
\text { contenido curricular. }\end{array}$ & $\begin{array}{l}\text { Exhibidores } \\
\text { museográficos. }\end{array}$ \\
\hline Exposiciones orales: & $\begin{array}{l}\text { Selección de un tema curri- } \\
\text { cular y/o de interés perso- } \\
\text { nal, que para su planeación } \\
\text { se concreta por escrito. Su } \\
\text { transmisión es oral ante } \\
\text { algún público, ya sea «en } \\
\text { clase o en otro tipo de foro» } \\
\text { (Díaz Barriga, 2006). Se } \\
\text { puede apoyar con material } \\
\text { visual y/o auditivo. }\end{array}$ & Presencia física. \\
\hline
\end{tabular}




\begin{tabular}{|c|c|c|}
\hline $\begin{array}{l}\text { PRODUCTO DE } \\
\text { APRENDIZAJE } \\
\text { ACADÉMICO }\end{array}$ & DESCRIPCIÓN & MODALIDAD \\
\hline Libros: & $\begin{array}{l}\text { «Al constituir la fuente más } \\
\text { antigua del saber» (Negrete, } \\
2008 \text { ), son posibilidades } \\
\text { cuyo exterior (imagen) e } \\
\text { interior (contenido) los con- } \\
\text { forman como científicos } \\
\text { (apegados a la investigación } \\
\text { formal) y de divulgación } \\
\text { (cercanos a la cotidianidad, a } \\
\text { la subjetividad del autor). Su } \\
\text { contenido y publicación } \\
\text { implican tiempo extenso de } \\
\text { investigación y escritura. }\end{array}$ & $\begin{array}{l}\text { Impreso. } \\
\text { Electrónico. } \\
\text { Audio. }\end{array}$ \\
\hline Material didáctico: & $\begin{array}{l}\text { Juegos, juguetes, objetos } \\
\text { dinámicos manipulables, } \\
\text { visuales y/o audibles, elabo- } \\
\text { rados con especificidad, o } \\
\text { bien, para hacer uso de los ya } \\
\text { existentes y darles un objeti- } \\
\text { vo determinado. Apoyan a } \\
\text { los contenidos curriculares. }\end{array}$ & $\begin{array}{l}\text { Materiales } \\
\text { manipulables. } \\
\text { Impreso. } \\
\text { Electrónico. } \\
\text { Audio. }\end{array}$ \\
\hline Material proyectivo: & $\begin{array}{l}\text { Expresiones artísticas surgi- } \\
\text { das de proyecciones persona- } \\
\text { les que son extraídas del con- } \\
\text { tenido curricular. Ejemplos: } \\
\text { pinturas, esculturas, letra } \\
\text { y/o música de canciones, } \\
\text { guiones teatrales, guiones } \\
\text { cinematográficos, poesías, } \\
\text { cuentos, novelas, historias de } \\
\text { vida, entrevistas. }\end{array}$ & $\begin{array}{l}\text { Impreso. } \\
\text { Electrónico. } \\
\text { Audio. } \\
\text { Expresiones } \\
\text { kinestésicas. }\end{array}$ \\
\hline
\end{tabular}




\begin{tabular}{|c|c|c|}
\hline $\begin{array}{l}\text { PRODUCTO DE } \\
\text { APRENDIZAJE } \\
\text { ACADÉMICO }\end{array}$ & DESCRIPCIÓN & MODALIDAD \\
\hline $\begin{array}{l}\text { Medios de comunicación } \\
\text { en línea (chat / messenger / } \\
\text { foro de discusión, mensaje } \\
\text { de celular): }\end{array}$ & $\begin{array}{l}\text { «Protocolos de comunica- } \\
\text { ción en tiempo real basados } \\
\text { en texto», (García Fernández } \\
\text { y Bringué, 2007) desde una } \\
\text { computadora o teléfono } \\
\text { celular (cuya organización se } \\
\text { ordena con base en temas } \\
\text { específicos extraídos del } \\
\text { contenido). Aportan desde } \\
\text { breves comentarios hasta } \\
\text { profundidad en la informa- } \\
\text { ción. Pueden ser de acceso } \\
\text { público o restringido; el } \\
\text { número de participantes es } \\
\text { inagotable. El profesor ha de } \\
\text { ser el mediador y puede } \\
\text { basar los contenidos de las } \\
\text { conversaciones en preguntas } \\
\text { generadoras. Posibilitan } \\
\text { también el intercambio de } \\
\text { documentos electrónicos. }\end{array}$ & $\begin{array}{l}\text { Electrónico. } \\
\text { Audio. } \\
\text { Video. }\end{array}$ \\
\hline Notas divulgativas: & $\begin{array}{l}\text { Documento cuyo contenido } \\
\text { se planea con base en un } \\
\text { tema concreto del contenido } \\
\text { curricular y que expresa, } \\
\text { desde diversos puntos de } \\
\text { vista, dicho tema. }\end{array}$ & $\begin{array}{l}\text { Impreso. } \\
\text { Electrónico. } \\
\text { Audio. }\end{array}$ \\
\hline
\end{tabular}




\begin{tabular}{|c|c|c|}
\hline $\begin{array}{l}\text { PRODUCTO DE } \\
\text { APRENDIZAJE } \\
\text { ACADÉMICO }\end{array}$ & DESCRIPCIÓN & MODALIDAD \\
\hline Página web: & $\begin{array}{l}\text { Espacio electrónico ubicado } \\
\text { en la World Wide Web (www) } \\
\text { que puede utilizarse con } \\
\text { fines académicos para expre- } \\
\text { sar visual, auditiva y/ o inte- } \\
\text { ractivamente, contenidos } \\
\text { curriculares generales y/o } \\
\text { específicos acerca de diversi- } \\
\text { dad de temas, disciplinas y } \\
\text { ciencias. Hospeda en hiper- } \\
\text { texto o hipermedia una } \\
\text { amplia gama de posibilidad } \\
\text { de actividades como lectura, } \\
\text { escritura, interacción, videos, } \\
\text { audio, juegos, artículos espe- } \\
\text { cializados, libros, etcétera, que } \\
\text { se encuentran vinculados } \\
\text { para remitir y referenciar unos } \\
\text { sitios a otros según el tema. }\end{array}$ & $\begin{array}{l}\text { Electrónico } \\
\text { multimedia. }\end{array}$ \\
\hline Portafolios: & $\begin{array}{l}\text { Colección de trabajos-eviden- } \\
\text { cia, elaborados ex profeso, en } \\
\text { un período de tiempo, para } \\
\text { mostrar lo aprendido con } \\
\text { base en reflexiones. «El mate- } \\
\text { rial que se reúne es indicativo } \\
\text { del progreso hacia los resul- } \\
\text { tados esenciales» (National } \\
\text { Education Association, 1993), } \\
\text { planeados con anticipación. }\end{array}$ & $\begin{array}{l}\text { Impreso. } \\
\text { Electrónico. }\end{array}$ \\
\hline
\end{tabular}




\begin{tabular}{|c|c|c|}
\hline $\begin{array}{l}\text { PRODUCTO DE } \\
\text { APRENDIZAJE } \\
\text { ACADÉMICO }\end{array}$ & DESCRIPCIÓN & MODALIDAD \\
\hline $\begin{array}{l}\text { Presentaciones } \\
\text { multimedia: }\end{array}$ & $\begin{array}{l}\text { Son diapositivas electrónicas } \\
\text { que se elaboran con texto, } \\
\text { imágenes, esquemas, gráfi- } \\
\text { cas, fotografías, sonidos, } \\
\text { videos, etcétera. Para fines } \\
\text { académicos son útiles para } \\
\text { presentar temas curriculares. } \\
\text { Se suelen utilizar como apo- } \\
\text { yos didácticos en el aula ya } \\
\text { que pueden proyectarse con } \\
\text { ayuda de un cañón o de un } \\
\text { retroproyector. }\end{array}$ & $\begin{array}{l}\text { Impreso en papel. } \\
\text { Impreso en acetato. } \\
\text { Electrónico. }\end{array}$ \\
\hline Reflexólogo: & $\begin{array}{l}\text { Documento en el que se } \\
\text { «presenta un reporte con los } \\
\text { temas centrales y sus reflexio- } \\
\text { nes personales» (Díaz Barriga, } \\
\text { 2006), concretas y abiertas, } \\
\text { inferidas de la selección de } \\
\text { lecturas, películas, documen- } \\
\text { tales relacionados con los con- } \\
\text { tenidos curriculares. }\end{array}$ & $\begin{array}{l}\text { Impreso. } \\
\text { Electrónico. } \\
\text { Audio. }\end{array}$ \\
\hline Revistas: & $\begin{array}{l}\text { Tienen como finalidad «apor- } \\
\text { tar información actualizada» } \\
\text { (Negrete, 2008), tanto científi- } \\
\text { ca como de divulgación, plas- } \\
\text { mada en una serie de artícu- } \\
\text { los y comentarios; se publican } \\
\text { periódicamente y son exper- } \\
\text { tos quienes colaboran en su } \\
\text { elaboración, permitiendo una } \\
\text { riqueza cultural y científica } \\
\text { precisa, y concretada en el } \\
\text { contexto donde se publica. }\end{array}$ & $\begin{array}{l}\text { Impreso. } \\
\text { Electrónico. } \\
\text { Audio. }\end{array}$ \\
\hline
\end{tabular}




\begin{tabular}{|l|l|l|}
\hline $\begin{array}{l}\text { PRODUCTO DE } \\
\text { APRENDIZAJE } \\
\text { ACADÉMICO }\end{array}$ & \multicolumn{1}{|c|}{ DESCRIPCIÓN } & MODALIDAD \\
\hline Videos: & $\begin{array}{l}\text { Documentos fílmicos cuyo } \\
\text { objetivo es transmitir con } \\
\text { imágenes y sonido un apren- } \\
\text { dizaje derivado del conteni- } \\
\text { do curricular expresado por } \\
\text { medio de animaciones cari- } \\
\text { caturizadas, actuación de } \\
\text { personas, documental o } \\
\text { combinación de varias. } \\
\text { Visual. } \\
\text { Audio. }\end{array}$ & \\
\hline
\end{tabular}

Estas opciones para mostrar el aprendizaje, son meras propuestas incentivadoras que permiten seleccionar lo que mejor evidencie el estilo del estudiante y concuerde con los contenidos y con el hacer con sentido. Todos los productos de aprendizaje académico propuestos, son conocidos en el medio educativo, por lo que su presencia en este trabajo no implica ni pretende innovaciones, sino opciones para un mejor desarrollo del proceso enseñanza-aprendizaje; su aplicación será viable de acuerdo a la capacidad creativa del estudiante y del docente.

Si el docente ofrece variedad de opciones para que el estudiante exprese lo aprendido en la teoría y en la práctica, se asegura, un poco más, un aprendizaje profundo, así como también «fortalecer la misión y la visión del modelo educativo de las instituciones educativas» (López Carrasco, 2008) a las que se pertenece. 


\section{REFLEXIONES FINALES}

Los contenidos curriculares en el aula universitaria, son los ejes que permiten al pensamiento, tanto del docente como del estudiante, complejizarse para continuar su desarrollo.

Para que el pensamiento complejo encuentre un sentido como aportador a la educación se ha de expresar en un hacer con sentido, en actividades en y para el mejoramiento de la vida individual y colaborativa.

Cada persona es unicidad que aprende de acuerdo a su particular manera de ser y de estar en la realidad, por lo que la enseñanza ha de permitir tantos estilos como individuos existen. El camino que se escoja para evidenciar el aprendizaje es lo de menos, siempre y cuando se utilice para educarse mostrando lo permanente de lo cambiante.

El docente puede permitir a los estudiantes plena libertad para elegir su camino de aprendizaje, y así mostrar lo aprendido, considerando la elaboración y entrega de productos de aprendizaje académico que evidencien lo obtenido, teniendo clara la meta final para el logro de un aprendizaje profundo.

La enseñanza y el aprendizaje profundo conllevan conocimientos, habilidades y actitudes adecuados a la naturaleza humana, para que en su momento sean compartidos a y con los demás. Para el logro de la dualidad profunda se requiere, por parte del docente y del estudiante, comunicación, seguimiento, acompañamiento, flexibilidad, reflexión, argumentación y humildad para reconocer la falibilidad y corregirla ${ }^{13}$.

${ }^{13}$ «Solo el espíritu crítico podrá salvar al hombre de errores, y de los ludibrios de toda especie a que está sujeto, en todos los sectores. El desarrollo de dicho espíritu no es privilegio de ninguna disciplina. Todas se prestan admirablemente para este fin. Para ello dependen del sentido de vitalidad y de articulación con la realidad viva y palpitante que se les confiere. [...] que la escuela abandone de una buena vez los métodos de enseñanza basados en la memorización y en la repetición [...] ya que atrofian el raciocinio, la simple memorización se opone al dinamismo de la inteligencia anulándolo» (Nérici, 1969); si bien es cierto y evidente que la memoria, como proceso mental,es trascendente para el aprendizaje en cuanto a retención y cobijo, más no para una reproducción mimética, sino para una complejización elaborada que permita un pensar complejo con sentido crítico. 
Actualmente la pedagogía requiere ser innovadora, propositiva y arriesgada para probar nuevos caminos que medien entre el pensar complejo y el actuar ético, hasta lograr una congruencia.

\section{REFERENCIAS BIBLIOGRÁFICAS}

ANDERSON, J.R., Aprendizaje y memoria: un enfoque integral, México, Mc Graw Hill, 2001.

BERNAL GONZÁLEZ, M. y MEZA MEJÍA, M., Educatividad y educabilidad, México, Minos Tercer Milenio/Universidad Panamericana, 2007.

BIGGS, J., Calidad del aprendizaje universitario, Madrid, Narcea, 2005.

COLOM, A., La (de)construcción del pensamiento pedagógico. Nuevas perspectivas en teoría de la educación, Barcelona, Paidós, 2002.

DÍAZ BARRIGA, F., Enseñanza situada: vínculo entre la escuela y la vida, México, Mc Graw Hill, 2006.

GARCÍA FERNÁNDEZ, F. y BRINGUÉ, X., Educar hijos interactivos, una reflexión práctica sobre las pantallas, España, Rialp/Instituto de Ciencias para la Familia, Universidad de Navarra, España, 2007.

GUTIÉRREZ MARTÍNEZ, F., Teorías del desarrollo cognitivo, Madrid, Mc Graw Hill, 2005.

LÓPEZ CARRASCO, M., Nuevas ignorancias, nuevas alfabetizaciones: lecturas caleidoscópicas en la sociedad de la información, Magistralis, XIII (27), 2006, p. 9-17.

Aprendizaje situacional: una perspectiva integradora apoyada en TIC. Memorias del congreso "Miradas constructivistas y su incidencia en la práctica docente», Oaxaca, México, 2008. 
MORIN, E., Educar en la era planetaria, España, Gedisa, 2003.

Gedisa, 2004.

, Introducción al pensamiento complejo, México,

NATIONAL EDUCATION ASSOCIATION, National Education

Association, Recuperado el enero de 2010, de Tools and Ideas, en Association Representative Resources, en: [http:/ / www.nea.org/index.html], 1993.

NEGRETE, J.A., Estrategias para el aprendizaje, México, Limusa, 2008.

NÉRICI, I.G., Hacia una didáctica general dinámica, Buenos Aires, Argentina, Kapelusz, 1969.

SALINAS, J.; PÉREZ, A. y BENITO de, B., Metodologías centradas en el alumno para el aprendizaje en red, Madrid, España, Síntesis, 2008.

SIEMENS, G., Conectivismo: Una teoría de aprendizaje para la era digital (D. E. Leal Fonseca, Trad.), Estados Unidos de Norteamérica, Creative Commons 2.5., 12-XII-2004.

UNIVERSIDAD DE LA REPÚBLICA, Características deseables de la formación del estudiante al ingreso a la universidad, Universidad de la República, Comisión Sectorial de Enseñanza, Subcomisión Coordinadora, Universidad de la República, Uruguay, 2004.

UNIVERSIDAD DEL SALVADOR (USAL), ¿Qué es pensamiento complejo y complejidad?, Instituto Internacional para el Pensamiento Complejo (IIPC), Vicerrectorado de Investigación y Desarrollo, recuperado en enero de 2010, en: [http:/ / www.complejidad.org/cms / ?q=node/3], 2007.

VILLALOBOS PÉREZ-CORTÉS, E.M., Educación y estilos de aprendizaje-enseñanza, México, Cruz O/Universidad Panamericana, 2003.

, Didáctica integrativa y el proceso de enseñanza aprendizaje, México, Trillas, 2006.

VILLARUEL, M., «La práctica educativa del maestro mediador», Revista Iberoamericana de Educación, 3(50), 2009. 